\section{Hepatitis E: Are Rheumatic Patients at Risk?}

\section{To the Editor:}

Hepatitis E virus (HEV) is a major cause of acute hepatitis in developing countries, but remains infrequent in industrialized countries despite a growing number of cases ${ }^{1}$. It is a zoonosis related to domestic and also wild animals. In epidemic conditions HEV is transmitted mainly by drinking fecal-contaminated water, but it can also be transmitted person to person, or mother to fetus, and even through contaminated transfusions. Sporadic hepatitis E seems to be the most common manifestation in industrialized countries ${ }^{2}$. In France, genotype 3 is the most common. HEV infection is usually self-limited, symptomatic or asymptomatic, with possible acute hepatitis. Fulminant hepatitis may be observed in pregnant women and patients with underlying liver disease. Chronic infections can be detected in patients with transplants, lymphoma, leukemia with reactivation, in immunocompromised children, and in patients infected with human immunodeficiency virus.

We describe a patient with rheumatoid arthritis (RA), treated with rituximab (RTX) and methotrexate (MTX), who had liver enzyme elevations and HEV infection.

RA was diagnosed in 1993 in a man, then 40 years old, living in Corsica, with no notable medical history. Since 2008 he had been receiving a combination of weekly MTX $15 \mathrm{mg}$ and RTX as 2 infusions: $1000 \mathrm{mg}$ by intravenous (IV) infusion, followed by a second $1000 \mathrm{mg}$ IV infusion 2 weeks later. The course was repeated every 6 months, with the last course in March 2011. At that time the alanine aminotransferase (ALT) level was $24 \mathrm{IU} / 1$ and aspartate aminotransferase (AST) was $25 \mathrm{IU} / 1$. In June 2011, he was found to have anorexia, diarrhea, and abdominal pain and tenderness as well as painful hepatomegaly. He was given metronidazole 1 $\mathrm{g} /$ day between June 23 and July 8 .

On hospital admission August 16, ALT level was 362 IU/l, AST 143 IU/l, $\gamma$-glutamyl transferase was $251 \mathrm{IU} / 1$, alkaline phosphatase was 144 IU/l, and bilirubin was $13 \mu \mathrm{mol} / 1$. HEV genotype 3 infection was diagnosed by reverse-transmission polymerase chain reaction, with HEV RNA in serum and stools, and concurrently with anti-HEV IgM in serum. A liver biopsy showed acute and chronic lesions, described during viral hepatitis E infection and eosinophilia, which could point to a possible drug-related cause. Fibrosis was classified as grade F0.

Ribavirin $400 \mathrm{mg}$ twice a day was given for 3 months. On August 30 the ALT level was $1095 \mathrm{IU} / 1$, AST was $679 \mathrm{IU} / 1, \gamma$-glutamyl transferase was $251 \mathrm{IU} / 1$, alkaline phosphatase was $144 \mathrm{IU} / 1$, and bilirubin was $13 \mu \mathrm{mol} / 1$.

The patient improved progressively and recovered fully within 3 months after onset. Liver function measures returned to normal limits: AST 26 IU/1, ALT 18 IU/l, and serum was clear of HEV RNA. RTX and MTX were reintroduced on November 29 without problems. No source for the HEV transmission including travel in endemic countries, drinking unsafe water, or eating undercooked pork could be identified.

The seroprevalence rate of IgG anti-HEV antibodies in France was $3.2 \%$ in blood donors in $2007^{3}$, with large variations in different regions ${ }^{4}$. Because chronic immunosuppression is associated with increased viral replication and accelerated disease course, infections and viral reactivations may possibly arise in patients treated with $\mathrm{RTX}^{5,6,7}$. Cases of hepatitis E during treatment with RTX are rare or are not reported. To our knowledge only 1 case report of hepatitis $E$ has been published ${ }^{8}$, in a patient with malignant non-Hodgkin's lymphoma, and no case of hepatitis E has been reported in patients with RA.

The incubation period of HEV infection ranges from 2 to 6 weeks ${ }^{1}$. In our patient, according to the low severity of the case and the inverse relationship between severity of disease and incubation period, we can estimate that the period of contamination was probably in the second half of May 2011. In areas of low endemicity, clinical presentations can be icteric hepatitis, anicteric nonspecific illness, and often unexplained liver enzyme anomalies ${ }^{9}$.

As is often the case in sporadic appearance of disease, we were unable to confirm the source of transmission. A substantial body of data indicates that HEV infection is a porcine zoonosis, as pigs and wild boars are commonly infected. The source and route of autochthonous HEV infection are not clearly established, but recent recovery of HEV RNA genotype 3 in traditional pig liver sausages (figatelli) purchased in supermarkets, with statistically significant genetic links with sequences recovered from patients, strongly supports the hypothesis of HEV infection through ingestion of figatelli ${ }^{10}$. Our patient was living in Corsica, where consumption of figatelli is common and this kind of transmission is a possibility.

Although rare, the possibility of hepatitis E viral infection must be kept in mind in treated patients with RA when there is an unexplained increase in liver enzymes.

CHRISTIAN H. ROUX, MD, Service de Rhumatologie, Academic Hospital l'Archet 1, Nice; RODOLPHE ANTY, MD, Gastroenterology, CHU l'Archet 1, Nice; STEPHANIE PATOURAUX, MD,

Anatomopathology, CHU Pasteur, Nice; LIANA EULLER-ZIEGLER, MD, Rheumatology, Academic Hospital l'Archet 1, Nice, France. Address correspondence to Dr. Roux; E-mail: roux101fr@yahoo.fr

\section{REFERENCES}

1. Kamar N, Bendall R, Legrand-Abravanel F, Xia NS, Ijaz S, Izopet J, et al. Hepatitis E. Lancet 2012;379:2477-88.

2. Teshale EH, Hu DJ. Hepatitis E: Epidemiology and prevention. World J Hepatol 2011;3:285-91.

3. Boutrouille A, Bakkali-Kassimi L, Crucière C, Pavio N. Prevalence of anti-hepatitis E virus antibodies in French blood donors. J Clin Microbiol 2007;45:2009-10.

4. Renou C, Moreau X, Pariente A, Cadranel JF, Maringe E, Morin T, et al. A national survey of acute hepatitis $\mathrm{E}$ in France. Aliment Pharmacol Ther 2008;27:1086-93.

5. Rafailidis PI, Kakisi OK, Vardakas K, Falagas ME. Infectious complications of monoclonal antibodies used in cancer therapy: A systematic review of the evidence from randomized controlled trials. Cancer 2007;109:2182-9.

6. Spina M, Jaeger U, Sparano JA, Talamini R, Simonelli C, Michieli $\mathrm{M}$, et al. Rituximab plus infusional cyclophosphamide, doxorubicin, and etoposide in HIV associated non-Hodgkin lymphoma: Pooled results from 3 phase 2 trials. Blood 2005;105:1891-7.

7. Aksoy S, Harputluoglu H, Kilickap S, Dede DS, Dizdar O, Altundag K, et al. Rituximab-related viral infections in lymphoma patients. Leuk Lymphoma 2007;48:1307-12.

8. Ollier L, Tieulie N, Sanderson F, Heudier P, Giordanengo V, Fuzibet JG. Chronic hepatitis after hepatitis E virus infection in a patient with non-Hodgkin lymphoma taking rituximab. Ann Intern Med 2009;150:430-1.

9. Mansuy JM, Peron JM, Abravanel Poirson H, Dubois M, Miedouge M, Vischi F, et al. Hepatitis E in the south west of France in individuals who have never visited an endemic area. J Med Virol 2004;74:419-24

10. Colson P, Borentain P, Queyriaux B, Kaba M, Moal V, Gallian P, et al. Pig liver sausage as a source of hepatitis $\mathrm{E}$ virus transmission to humans. J Infect Dis 2010;202:825-34.

J Rheumatol 2013;40:1; doi:10.3899/jrheum.120599 